\title{
The Role of Gender on the Isolation of Teaching Effectiveness Factors by Nigerian Senior Secondary School Chemistry Students
}

\author{
Toyin E. Owoyemi ${ }^{1} \&$ Francis A. Adesoji ${ }^{2}$ \\ ${ }^{1}$ Adeyemi College of Education, Ondo, Nigeria \\ ${ }^{2}$ Teacher Education Department, University of Ibadan, Nigeria \\ Correspondence: Toyin E. Owoyemi, Adeyemi College of Education, Ondo, Nigeria. E-mail: \\ toyinowoyemi2006@yahoo.com \\ Received: September 20, 2012 Accepted: November 27, 2012 Online Published: January 28, 2013 \\ doi:10.5539/ass.v9n2p270 \\ URL: http://dx.doi.org/10.5539/ass.v9n2p270
}

\begin{abstract}
Students' evaluation of teaching is one area of educational research that is becoming increasingly emphasised in recent times in Nigeria, but limited attention is still given to the identification of teaching effectiveness factors from students' point of view, in order to develop a valid and reliable instrument. Students' evaluation is commonly used in developed countries to provide information that could be used by teacher to improve his/her teaching and by administrators to make personnel decisions like promotion. This study therefore analysed the isolated teaching effectiveness factors in chemistry according to the gender of the students. The study adopted survey research design of ex-post facto type. Two thousand nine hundred and eighty eight SSII chemistry students participated, using multistage and stratified random sampling techniques from the six states in the Southwest geopolitical zone of Nigeria. Data collected through validated and reliable "Students' Evaluation of Teaching Effectiveness Scale (0.78)" were analysed using factor analysis. The study found that there are significant similarities in the ratings of the teaching effectiveness factors in Chemistry classroom due to gender. Each gender profile reveals 11 pattern of underlying influence of which 7 are common to both gender. Educational planners, policy makers and administrators are therefore urged to work out modalities for the development and implementation of students' evaluation of teaching effectiveness instrument for use at the secondary level of education.
\end{abstract}

Keywords: role, gender, isolation, teaching effectiveness, factors, chemistry, students

\section{Introduction}

Despite a large contemporary literature on student evaluations, gender effects are infrequently mentioned and the available studies on it have been controversial and contradictory (Freeman, 1994; Marsh and Roche, 1997). Many researchers, mindful of the controversy, have concluded that most evaluation instruments are multi-dimensional and result in global scores that can be misleading and difficult to interpret (Greenwald, 1997; Marsh et al, 1997; Mckeachie, 1997).

One of the major reasons why researchers on students' evaluation appear controversial in education circles is that such student characteristics as gender whose influence could be significant are often neglected thereby raising validity question (Riger, 1993). But in the literature, some researchers showed that students' gender has little or no effect on their ratings of lecturers teaching effectiveness (Davis, 1993). Other researchers who have reported little or no relationships between students' gender and their rating of instructors are Basow and Silberg, (1987); Bennet, (1982); Marsh et al, (1992); Stathan, Richardson and Cook (1991).

In view of these controversies it is deemed necessary to look at the effect of gender on students' evaluation of teaching effectiveness.

\section{Literature Review}

From the literature on student evaluations, gender effects are seldomly mentioned and the available studies on it have been controversial and contradictory (Freeman, 1994; Marsh et al, 1997; Greenwald, 1997; Mckeachie, 1997).

However a number of works have recorded the influence of students' gender on their ratings of lecturers. For 
instance, Krahn and Bowlby (1997) investigated the possible influence of gender on students' evaluation of teaching effectiveness of lecturers in University of Alberta. They made use of 1452 undergraduates. Findings indicated that students' gender influenced their pattern of rating. Chang (1997), also conducted a study which examined the effect of gender on students rating of teacher performance in a Taiwanese college. A total of 9843 students were asked to rate their lecturers totaling 132. Instruments used were evaluation forms containing 13 questions that focused on four dimensions of teacher performances. Results indicated that male students rated male lecturers higher than their female counterparts. Boggs and Wiseman (1995) in their own study examined the role of gender in University Students' Evaluation of lecturers. Results of the analysis of 120 students' responses showed the presence of subtle gender biases in the overall students' evaluation. In a similar vein, Tatro (1995) identified gender differences in college students' rating of their lectures. The result showed that female lecturers were found to have received higher ratings than their male colleagues who appear to be conservative with the marks'.

Amin (1994) also compared the evaluation of 1064 male and female undergraduates in the University of Yaoundé, Cameroon. Their lecturer effectiveness was the focus of evaluation. Also, Luck (1993) discovered that male students rated male instructors higher than female instructors while female students rated female instructors higher than the males. Another study by Feldman (1993) investigated college students' evaluation of their male and female teachers. Results revealed that gender interaction within the study was significant. In a similar study Vanoo Stendorp (1999) found that females were rated higher than the males by female raters while the male students rated male lecturers higher than the female lecturers.

According to Arreola (1995), results in the literature regarding gender and ratings are inconsistent. Aleamoni and Hexner (1980) found no significant relationship between ratings and gender (of the instructor or student). Other researchers (Doyle and Whitely, 1974;McKeachie et al., 1964 cited in Arreola, 1995) support this conclusion. In Costin et al.'s (1971) review of the research; they also cite seven studies that confirm the absence of significant differences between the ratings made by male or female students, and the ratings received by male and female instructors.

In contrast, Costin et al and Aleamoni and Hexner also cite a study by Bendig (1952) cited in Costin et al., 1971) showed that female students tended to be slightly more critical of their male instructors than were their fellow male students. And another study by Walker (1969 cited in Costin et al., 1971) found that female students rated female instructors "significantly higher" than they rated male instructors (p. 520).Marsh and Roche (1997) concluded that the gender issue has "mixed findings but little or no effect" (p. 1194).

Since there is no generally agreed influence of gender on students' evaluation of teaching, the present study deemed it necessary to look at the effect of gender on the students' evaluation of teaching effectiveness.

\section{Research Question}

Does Gender influence the ratings of the senior school Chemistry students of teaching effectiveness factors?

\section{Methodology}

\subsection{Research Design}

This study is an ex-post facto type with a survey design. This is appropriate since the researcher has no direct control of the independent variables as their manifestations have already existed.

\subsection{Population and Sampling Technique}

The target population of the study was Senior Secondary School Class two (SS II) chemistry students in the six South Western States of Nigeria. The sample size was 2988 using multistage and stratified random sampling techniques.

\subsection{Research Instrument}

The development of the instrument was based on previous research works on students' evaluation of teaching effectiveness (March, 1982, Onocha, 1996). A large pool of items was obtained from literature together with interviews held with teachers and students about what makes up effective teaching. These were used to select items and the items selected covered all the major variables identified from the review of past literature on teaching effectiveness. SETES was scored based on a four-point Likert Scale ranging from strongly Agree, Agree, and Disagree to Strongly Disagree. Positive statements are to be rated 4, 3, 2 and 1 respectively while the ratings for negative statements were reversed. 


\subsubsection{Validation and Reliability of Instrument}

Experts in item construction and evaluation assisted in the validation of the instrument. The language of presentation, clarity and applicability to the level of the participants were addressed. The instrument was also presented to experts in the field of science education and two secondary school chemistry teachers for content and construct validity. Based on their comments the initial 75 variables of SETES were reduced to 50 . The instrument was again subjected to reliability test using a comparable sample who did not take part in the main study. The scores were analysed using Cronbach alpha method. The alpha value obtained was 0.781 , which was quite high implying that the instrument is reliable.

\subsection{Procedure for Data Collection}

The researcher and two research assistants administered the instruments designed for the study to collect the required data directly from the participants.

\subsection{Data Analysis.}

Data collected were subjected to factor analysis with varimax rotation to answer the research questions raised.

\section{Findings and Discussion}

\subsection{Knowledge of the Subject Matter Factor}

This factor accounted for $19.121 \%$ of the total variance in male profile as first factor. In female profile this descriptive category is the $6^{\text {th }}$ pattern. In the female profile it accounts for $3.504 \%$ of the total variance. The model below gives the latent dimension for both male and female profiles.

$$
\begin{gathered}
\mathrm{F}_{1 \mathrm{~m}}=0.47 \operatorname{Var}_{7}+0.637 \operatorname{Var}_{8}+0.599 \operatorname{Var}_{10}+0.55 \operatorname{Var}_{12}+0.468 \operatorname{Var}_{18}+0.579 \operatorname{Var}_{21}+0.463 \operatorname{Var}_{38} \\
\mathrm{~F}_{1 \mathrm{f}}=0.809 \operatorname{Var}_{11}+0.824 \operatorname{Var}_{12}
\end{gathered}
$$

Where $\mathrm{F}=$ latent factor, $\mathrm{m}=$ male and $\mathrm{f}=$ female.

Although not all the same exact variables loaded on the two factors, all the variables centered on the same descriptive category. For instance, the variable $\operatorname{Var}_{12}$ loaded on the factor in the two profiles, the factor contributing $30.47 \%$ and $67.90 \%$ of the variances in the variable in male and female profiles respectively.

A plot of the vectors of the factors and $\operatorname{Var}_{12}$ "Apply the theories discussed in the teaching period during laboratory exercise" on Cartesian coordinates shows that it has higher inclination and stronger relationship with factor 1 in females profile than in male's profile. The length of the vector is smaller in female (31.79) profile than male's (32.21). Thus, the total variation is slightly higher in male by about $1.32 \%$
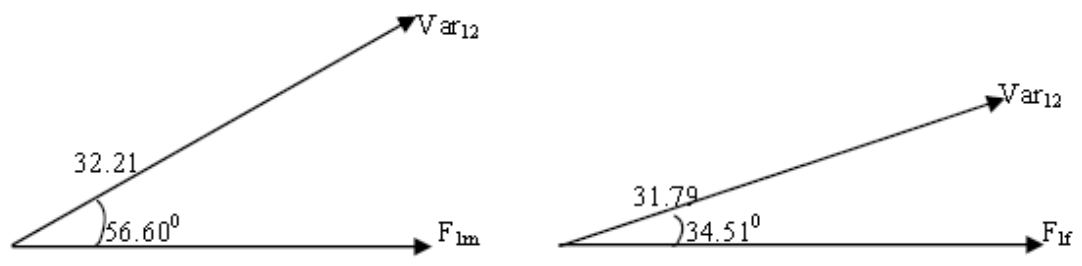

Figure 1. A plot of the vectors of the factors and $\operatorname{Var}_{12}$

Moreover, variable $\mathrm{Var}_{8}$, "Explain clearly and give notes" is not considered by the ratings of the female students as being very important to this latent factor in the female profile whereas in the male the vector is at angle $50.43^{0}$ to the factor. The vector is at angle $85.60^{\circ}$ with the factor in female profile. As the angle is very close to $90^{\circ}$ in female profile, it indicates a very low and negligible correlation between the variable and factor 1 . This factor accounts for only $0.57 \%$ of the variance in $\mathrm{Var}_{8}$. However, the total variation of this vector is 28.87 in female profile as against 29.34 of the male profile.
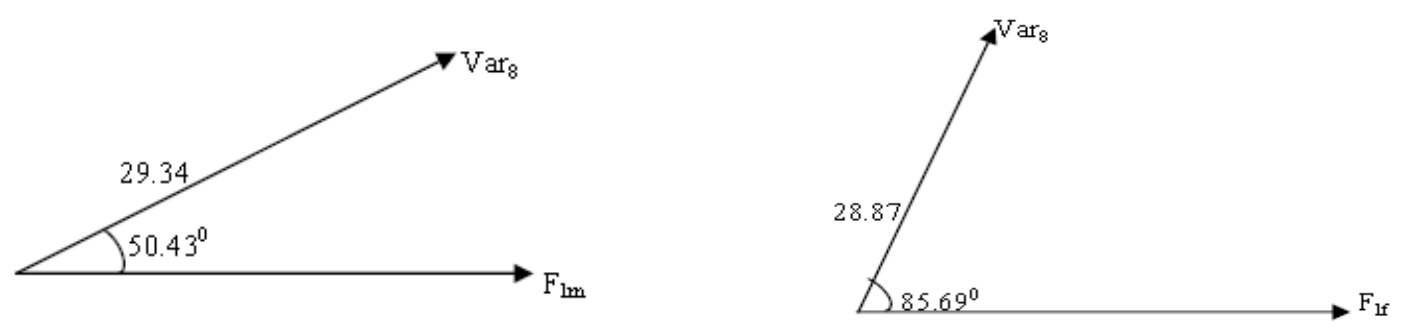

Figure 2. A plot of the vectors of the factors and $\mathrm{Var}_{8}$ 
In addition, vector of $\operatorname{Var}_{11}$ "Show a thorough knowledge of subject matter" has an angle $36^{\circ}$ with the vector, $\mathrm{F}_{1 \mathrm{f}}$ while it is negligible in the male profile.

\subsection{Give Adequate Assignment Factor}

This factor explained $7.088 \%$ of the total variance in the male profile. The highly loaded variables on the factor are: $\operatorname{Var}_{40}(0.567), \operatorname{Var}_{41}(0.491) \operatorname{Var}_{46}(0.501), \operatorname{Var}_{47}(0.567), \operatorname{Var}_{48}(0.654)$ and $\operatorname{Var}_{49}(0.495)$. The factor explained $42.77 \%, 32.15 \%$ and $25.1 \%$ in $\operatorname{Var}_{48}$, "Systematically supervise homework"; $\operatorname{Var}_{40}$, "Give adequate assignments after each lesson" and $\mathrm{Var}_{46}$ "Effectively use assignments to enhance learning" respectively. However, in female profile the factor is the $8^{\text {th }}$ one. It accounted for $2.107 \%$ with characteristics root of 1.053 . Its correlation with $\operatorname{Var}_{41}$, "Give adequate instructions concerning assignment" increased from 0.491 in male profile to 0.603 in female profile. The vector of $\operatorname{Var}_{41}$ form an angle of $60.59^{\circ}$ with length 30.72 and $52.91^{\circ}$ with length 28.66 on vector $F_{2 m}$ and $F_{2 f}$ respectively showing a relatively higher correlation and lesser total variation with $F_{2 f}$ than $F_{2 m}$
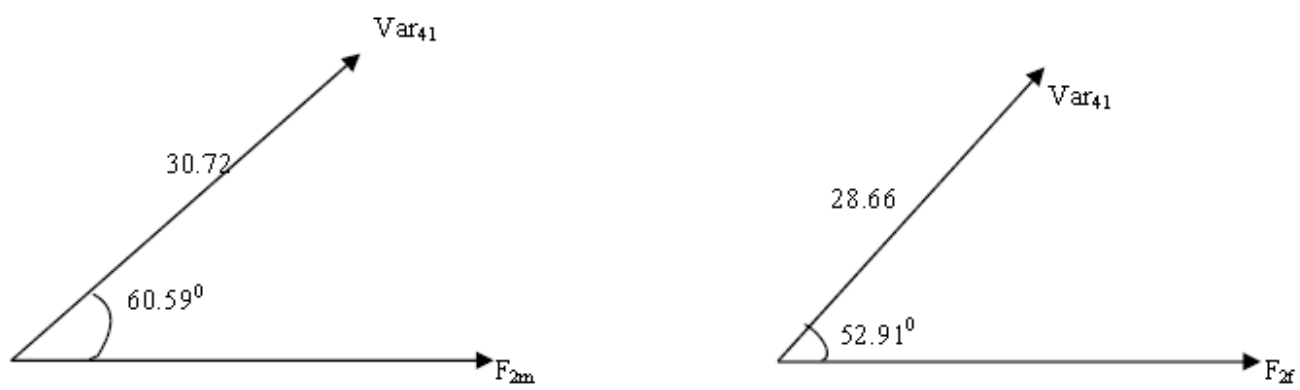

Figure 3. A plot of the vectors of the factors and $\operatorname{Var}_{41}$

Also while this descriptive category explained a total variance of $24.11 \%$ in the $\operatorname{Var}_{41}$ in male profile, it accounts for $36.36 \%$ of the total variance of $\operatorname{Var}_{41}$ in female profile.

\subsection{Dynamism of the Teacher Factor}

In the male profile, this factor accounts for $3.174 \%$ of the total variance and it is the $3^{\text {rd }}$ in strength and degree of comprehensiveness. There are three variables; $\operatorname{Var}_{4}, \operatorname{Var}_{13}$ and $\operatorname{Var}_{39}$ that load on the factor. The factor explained $69.89 \%, 59.44 \%$ and $74.65 \%$ of these variables respectively. The loaded variables have correlations $\mathrm{r}: 0.771 \leq \mathrm{r}$ $\leq 0.864$. This factor does not exist in the female profile. However, the $3^{\text {rd }}$ factor in the female profile is "Commitment". It explained $2.873 \%$ of the total variance of female profile. This common factor accounted for $36 \%$ of the variance in variable, $\operatorname{Var}_{18}$, "Be prompt and consistent in attending class". The vector of the variable $\operatorname{Var}_{18}$ is at an acute angle of $53.13^{\circ}$ with the common factor thus given a moderately high correlation $\mathrm{r}=0.6$. Other variables that loaded moderately high on the factor $\operatorname{are~} \operatorname{Var}_{8}(0.446), \operatorname{Var}_{21}(0.453)$ and $\operatorname{Var}_{40}(0.532)$.

\subsection{Feedback Factor}

This is the $4^{\text {th }}$ Pattern that accounts for the greatest regularity in the male profile. It accounts for $2.544 \%$ of the total variance in the profile. Two variables loaded moderately high on the feedback common factor. These are $\operatorname{Var}_{33}$ "Be concerned about students individual differences" and $\operatorname{Var}_{45}$ "Provide feedback on students" progress" the two variables have correlation $\mathrm{r}=0.519$ and $\mathrm{r}=0.562$ respectively.

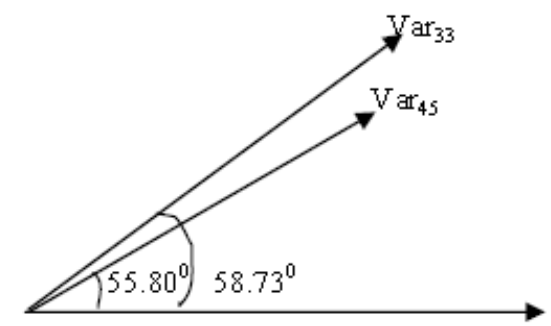

Figure 4. A plot of the vectors of the factor $\mathrm{F}_{4 \mathrm{~m}}, \operatorname{Var}_{33}$ and $\operatorname{Var}_{45}$

From the figure above, the variables correlated with the factor and it explains $26.24 \%$ and $31.58 \%$ of the variances in the variables. However, this factor does not exist at all in the female profile. Considering the loadings of the entire 50 variables on all the 11 factors it was discovered that the $\operatorname{var}_{33}$ "Be concerned about students' individual differences" is almost at an angle $90^{\circ}$ with all the factors in the female profile. 
Table 1. Correlation of $\operatorname{Var}_{33}$ with all factors

\begin{tabular}{cccc}
\hline Factor & Angle of inclination to the factor & Correlation with factor & $\%$ of variance explained by the factor \\
\hline 1 & $73.44^{0}$ & 0.285 & 8.12 \\
2 & $70.12^{0}$ & 0.340 & 11.56 \\
3 & $99.9^{0}$ & -0.172 & 2.96 \\
4 & $75.11^{0}$ & 0.257 & 6.60 \\
5 & $75.05^{0}$ & 0.258 & 6.66 \\
6 & $87.46^{0}$ & 0.044 & 0.20 \\
7 & $75.29^{0}$ & 0.254 & 6.45 \\
8 & $82.59^{0}$ & 0.129 & 1.66 \\
9 & $77.17^{0}$ & 0.222 & 4.93 \\
10 & $93.83^{0}$ & -0.066 & 0.45 \\
11 & $95.66^{0}$ & -0.098 & 0.97 \\
\hline
\end{tabular}

The table above reveals a striking relationship between the various delineated patterns in the female profile and the teachers concern with students' individual differences. The vector of the variable is either at an acute angle almost perpendicular to the latent factor or at obtuse angle indicating an inverse relationship with the factor. The correlation of the variable with each factor is very low hence its variance contribution is very infinitesimal and negligible. This implies that females cherish their privacy and thus, anything that will expose them or bring their individual differences into the public glare is not regarded as an important teaching effectiveness factors in a Chemistry classroom. It should be noted that this class of students are adolescent and thus want to protect their ego.

\subsection{Group Discussion Factor}

In the female profile, this is the $5^{\text {th }}$ factor and it contributes $3.344 \%$ to the total variance explained in the profile. There are two variables that loaded significantly high on the factor and the variables centered mainly on group discussion. The variables have significantly high correlations $\operatorname{Var}_{19}(0.611)$ and $\operatorname{Var}_{23}(0.710)$ with the factor. The common factor explained $37.33 \%$ and $50.41 \%$ total variance of the variables respectively. However, this latent pattern does not appear in the female profile. In addition the two variables on this descriptive category do not have any significant loadings on other factors in the female profile. Also in this profile the female students do not rank variables that deal with interpersonal relationship as teaching effectiveness factors in a Chemistry classroom.

\subsection{Good Sense of Humour Factor}

This factor is only peculiar to the male profile. It accounts for $3.259 \%$ of the total variance in the male profile. It is a specific factor and the only variable that loads on it has a correlation of $\mathrm{r}=0.58$.

\subsection{Communication Skills Factor}

This is the $7^{\text {th }}$ factor in both profiles indicating the same degree of strength. It accounted for $3.217 \%$ of the total variance explained in the male profile and $3.256 \%$ in the female. Thus, in both profiles, they represent almost the same degree of comprehensiveness. It is a specific factor in females. When represented in vector geometry, the dominant variable in the factor $\mathrm{Var}_{9}$ "Summarise major points" shows that in the female profile, the correlation is higher with the factor than male profile. Both vectors are in the same positive direction. Also the length of the vector is slightly higher in male profile than female. On the whole both profiles attach a higher premium to "Summarise major points" in a Chemistry classroom.
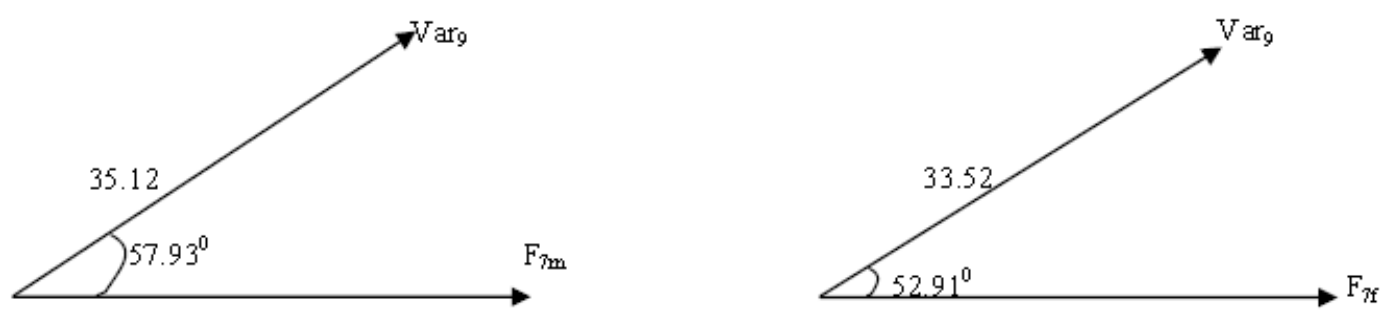

Figure 5. A plot of the vectors of the factors $\mathrm{F}_{7 \mathrm{~m}}, \mathrm{~F}_{7 \mathrm{f}}$ and $\mathrm{Var}_{9}$ 
The orthogonal factor accounted for $28.20 \%$ of the variance in the variable in the male profile while it accounts for $42.64 \%$ of the variance in the female profile. This shows that both male and female students recognize communication skills as an important factor for effective teaching of Chemistry.

\subsection{Good Rapport Factor}

This factor is the $8^{\text {th }}$ in male and $9^{\text {th }}$ in female. In both profiles it is a specific factor. It accounts for $2.785 \%$ in males profile and $2.469 \%$ in the female profile.

\subsection{Teacher-Student Interaction Factor}

Teachers - students Interaction is the $9^{\text {th }}$ construct in the male profile, and, accounts for $2.712 \%$ of the total variance explained. However, four variables loaded very high on the factor with correlation $r: 0.450 \leq r \leq 0.557$, in the female profile and the construct is the $4^{\text {th }}$ one. It accounts for $5.355 \%$ of the total variance explained in the female profile, thus it is more comprehensive and stronger in the female profile. Out of the four variables that loaded high in the female profile, two and only two loaded on the construct in the male profile. In Cartesian plane, the vectors of the constructs and the two variables $\operatorname{Var}_{25}$ : "Be friendly towards students" and $\operatorname{Var}_{27}$ "Be available to give help to students" are compared.
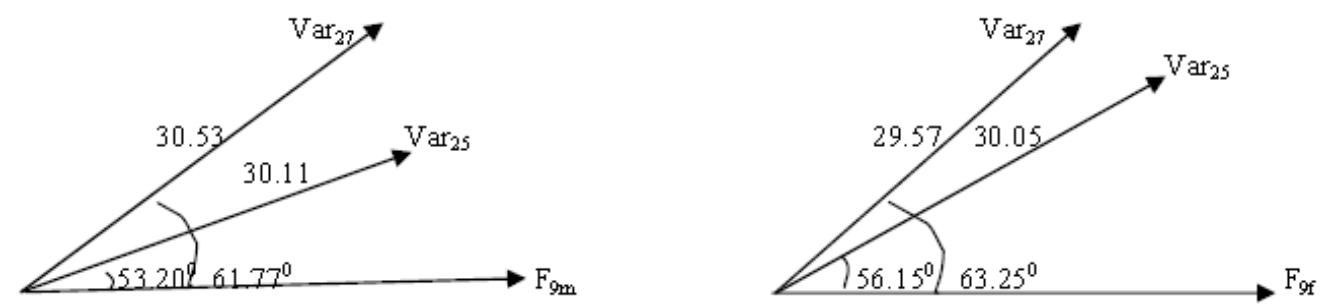

Figure 6. A plot of the vectors of the factors $\mathrm{F}_{9 \mathrm{~m}}, \mathrm{~F}_{9 \mathrm{f}}, \operatorname{Var}_{25}$ and $\operatorname{Var}_{27}$

From the above geometrical vectors, $\operatorname{Var}_{25}$ has a higher correlation with the factor than $\operatorname{Var}_{27}$ in male profile, whereas in the female profile, $\operatorname{Var}_{27}$ has a higher correlation with the factor than $\operatorname{Var}_{25}$. Nevertheless, the length of $\operatorname{Var}_{25}$ is almost the same in both profiles while the length of Var27 is about 3.25\% higher in male profile than female. This implies that the variability of the ratings is higher in male than female. On the other hand, the females are more consistent in the rating of $\operatorname{Var}_{27}$ "Be available to give help to students" than the males.

Also there is a peculiarity in one variable in female profile, that is, $\operatorname{Var}_{21}$, which indicates a factorial complexity of two and it loaded moderately high on both factor $3(0.453)$ and factor $4(0.543)$. This implies that the female students believe that "Make students feel free to ask questions and express their ideas" is a cogent pathogen of teachers "commitment" and "Teacher-student interaction".

\subsection{Statement of Objectives Facto}

In both profiles, this factor is the $10^{\text {th }}$ orthogonal factor. It accounts for $2.377 \%$ of the variations in male profile and $2.055 \%$ in the female profile. This means they have the same strength but slightly different in comprehensiveness. The factor is specific in female but has two variables loaded on it in male profile. $\operatorname{Var}_{1}$ contributes $54.91 \%$ in female but $26.01 \%$ in male profile. Moreover, the vector of $\operatorname{Var}_{1}$ intercepts female latent construct at acute angle $42.18^{\circ}$ and male latent construct at an acute angle $59.34^{0}$ indicating a grater correlation and influence in female profile than in male profile.

\subsection{Analytical Ability Factor}

Here also, this construct is a specific factor in male profile. Male and female students' believe that teacher's ability to identify salient and cogent points of his/her topic is tangential to effective teaching in a Chemistry classroom. It has a total eigenvalue of 1.010 and accounts for $2.302 \%$ of the total variance in the male profile. The common factor in male accounted for $36.12 \%$ of the variance in $\operatorname{Var}_{2}$ and is the only variable that loaded moderately high on the factor with a correlation $\mathrm{r}=0.601$. In female it is the $5^{\text {th }}$ factor with eigenvalue of 2.156 and explained $4.312 \%$ of the total variance. It predicts $33.41 \%, 24.06 \%, 20.80 \%$ and $23.72 \%$ of the variances in $\operatorname{Var}_{2}, \operatorname{Var}_{3}, \operatorname{Var}_{4}$ and $\operatorname{Var}_{10}$ respectively.

In addition there are 3 factors that exist in female profile but not in males. The most comprehensive factor in female is "Examination" with five variables loading moderately high. "Examination" explained $7.089 \%$ of the variation in female. The variables on the factor has correlation $\mathrm{r} ; 0.504 \leq \mathrm{r} \leq 0.611$. Also the $2^{\text {nd }}$ most comprehensive orthogonal factor in the female is "Proper Examination Management". It has correlation $r: 0.462$ $\leq \mathrm{r} \leq 0.596$. It accounts for $6.386 \%$ of the total variance in female. The female also consider the "Instructional 
materials usage" as important factor for teaching effectiveness in a Chemistry classroom. It accounts for $2.302 \%$ of the total variance in the profile. These three factors do not exist in male profile.

Table 2. Comparison of factor structure of male and female profiles

\begin{tabular}{lll}
\hline Root Mean Square & Coefficient of Congruence & Latent factors \\
\hline 0.2399 & 0.5464 & Knowledge of Subject Matter \\
0.2256 & 0.5361 & Assignment \\
0.1544 & 0.6116 & Communication Skills \\
0.2064 & 0.1286 & Good Rapport \\
0.2052 & 0.4882 & Teacher-Student Interaction \\
0.1555 & 0.4452 & Statement of Objectives \\
0.1899 & 0.4527 & Analytical Ability \\
\hline
\end{tabular}

The Table 2 above is the computation of root mean square (RMS) and coefficient of congruence (Co) to compare the factor structure of both male and female profiles. Out of the 11 factors that emerged in each profile, 7 of them appeared in both profiles. From the table the RMS is in the interval $0.1544<\mathrm{RMS}<0.23999$. All values are closer to zero than 2 and RMS $<0.5$ for every factor. This implies that there is a perfect match between male and female profiles both in pattern and magnitude. Moreover, the coefficient of congruence from the table also indicates that both male and female teaching effectiveness rating profiles show pattern and magnitude similarities.

\section{Conclusion}

The study found that there are significant similarities in the ratings of the teaching effectiveness factors in a Chemistry classroom due to gender. Each gender profile reveals 11 pattern of underlying influence of which 7 are common to both gender. The root mean square and coefficient of congruence measures indicate clearly that the two profiles are similar in pattern and magnitude though with slight variations in degree of comprehensiveness and strength.

However, four factors from each profile differentiate these profiles according to gender. While the male students believe in "Dynamism" of the Teacher in the class, "Feedback" on students' progress, "Group Discussion" and "Good Sense of Humour" of the teachers, the female students extended their interest to "Examinations", "Proper Classroom Management", "Commitment and Use of Instructional materials". Thus, while there is slight difference in factor pattern, the factor structures are similar.

\section{References}

Amin, M. E. (1994). Gender as a discriminatory factor in the evaluation of teaching. Assessment and Evaluation in Higher Education, 19(2), 135-143. http://dx.doi.org/10.1080/0260293940190206

Basows, S. A., \& Silberg, I. I. (1987). Students Evaluations of College Professors: Are male and female professors rated differently? Journal of Educational Psychology, 79(3), 308-314. http://dx.doi.org/10.1037/0022-0663.79.3.308

Bennett, S. K. (1982). Student perception of and expectations for male and female instructors: Evidence Relating to the Question of Gender Bias in Teaching Evaluation. Journal of Educational Psychology, 74(2), 170-179. http://dx.doi.org/10.1037/0022-0663.74.2.170

Boggs, C., \& Wiseman, J. M. (1995). The Role of Gender and Communicative Competence in University Students' Evaluation of their Teaching Assistants. Paper presented at the Annual Meeting of Speech Communication Association, Nov. 19-22.

Chang, T. S. (1997). Students' Rating of Instruction at Teachers College in Taiwan. Research Report MF/01/ University of Taiwan.

Costin, F., Greenough, W. T., \& Menges, R. J. (1971). Student ratings of college teaching: Reliability, validity and usefulness. Review of Educational Research, 41, 511-535.

Davis, B. G. (1993). Tools for Teaching. San Francisco. Jossey Bass.

Ediger, M. (1930). The Middle School Student and Interest in Reading. Reading Improvement, 29(3), 171-173. 
Feldman, K. A. (1993). College Students' Views of Male and Female College Teachers: Part II-Evidence from Students' Evaluations of their Classroom Teachers. Research in Higher Education, 34, 151-211. http://dx.doi.org/10.1007/BF00992161

Freeman, H. R. (1994). Student Evaluation of College Instruction: Effect of type of Course Taught, Instructor Gender and Gender Role and Student Gender. Journal of Educational Psychology, 86, 627-630. http://dx.doi.org/10.1037/0022-0663.86.4.627

Greenwald, A. G. (1997). Validity concerns and usefulness of student ratings of ratings of instructions. American Psychologist, 52, 1182-1186. http://dx.doi.org/10.1037/0003-066X.52.11.1182

Krahn, H., \& Bowlby, J. (1997). Good Teaching and Satisfied University Graduates. Canadian Journal of Higher Education, 27(2-3), 157-180.

Marsh, H. W., \& Dunkin, M. J. (1992). Students Evaluations of University Teaching: A Multidimensional perspective. In J. Smart (Ed.), Higher Education: Handbook of theory and Research (pp. 87-106). Agathon, New York. 8

Marsh, H. W., \& Roche, L. A. (1997). Making Students Evaluations of Teaching Effectiveness Effective: The Critical Issues of Validity, Bias, and Utility. American Psychologist, 52, 1187-1197. http://dx.doi.org/10.1037/0003-066X.52.11.1187

Mckeachie, W. J. (1997). Student ratings: The validity of use. American psychologist, 52, 1218-1225. http://dx.doi.org/10.1037/0003-066X.52.11.1218

Onocha, C. O. (1995). Students Evaluation Research in Nigeria: Validity Research in Nigeria. Nigeria Journal of Clinical and Counseling Psychology, (1), 31-39.

Riger, S. (1993). Gender and Teaching Evaluation. Evaluation Report, 18, 45-47.

Stathan, A., Richardson, L., \& Cook, J. A. (1991).Gender and University Teaching. A Negotiated Difference. Albany State University. Oxford: Pergamon.

Tatro, C. N. (1995). Gender Effects on Student Evaluation of Faculty. Journal of Research and Development, 28(93), 169-173.

Vanoo Stendorp, K. D. (1999). Effects of Students Gender Bias toward the Instructor and Classroom Management at the Secondary Level. M.ED. Dissertation, Michigan State University. 